\title{
Equivalent Circuit Modification for Organic Solar Cells
}

\author{
Nazmul Hossain ${ }^{1}$, Sayantan Das², Terry L. Alford ${ }^{2}$ \\ ${ }^{1}$ Department of Electrical Engineering, Arizona State University, Tempe, AZ, USA \\ ${ }^{2}$ School of Engineering of Matter, Transport and Energy, Arizona State University, Tempe, AZ, USA \\ Email: nhossai1@asu.edu, sdas30@asu.edu, TA@asu.edu
}

Received 30 March 2015; accepted 24 July 2015; published 27 July 2015

Copyright (C) 2015 by authors and Scientific Research Publishing Inc.

This work is licensed under the Creative Commons Attribution International License (CC BY).

http://creativecommons.org/licenses/by/4.0/

cc) (i) Open Access

\begin{abstract}
In this work, a newly fabricated organic solar cell based on a composite of fullerene derivative [6,6]-phenyl-C61 butyric acid methyl ester (PCBM) and regioregular poly (3-hexylthiophene) (P3HT) with an added interfacial layer of $\mathrm{AgO}_{\mathrm{x}}$ in between the PEDOT:PSS layer and the ITO layer is investigated and an equivalent circuit model is proposed for the device. Incorporation of the $\mathrm{AgO}_{\mathrm{x}}$ interfacial layer shows an increase in fill factor (by $\mathbf{3 3 \%}$ ) and power conversion efficiency (by 28\%). Moreover, proper correlation has been achieved between the experimental and simulated I-V plots. The simulation shows that device characteristics can be explained with accuracy by the proposed model.
\end{abstract}

\section{Keywords}

\section{Equivalent Circuit, Fill-Factor, Interfacial Layer, Organic Solar Cells, P3HT/PCBM}

\section{Introduction}

Organic solar cells (OSCs), offers tremendous promise as an alternative to conventional Si-based solar photovoltaics (PV) technology as it requires less production cost and effort because organic semiconductors are simple to process than the inorganic cells due to much lower processing temperatures [1]-[11]. Although it is in early stage of technology, the vision is mass production of these devices with less stringent and less thermal budget requirements than those needed for traditional silicon solar cells. The production potential may possibly exceed $1000 \mathrm{~m}^{2}$ per hour [5]. Because of the development of newer materials, new designs and interfacial layers it can exhibit very high power conversion efficiency (PCEs).

The most promising designs are a combination of electron-accepting and electron-donation molecular materials, so as to develop a p-n heterojunction. Efficient charge carrier extraction from the active layer to the re- 
spective electrodes is essential for optimal functioning of OSCs and depends on the character of the interface of each layer. One way to obtain efficient charge extraction is to match the work function of anode and cathode with the highest occupied molecular orbital (HOMO) and lowest unoccupied molecular orbital (LUMO) energies of the active layer [12] [13]. The introduction of self-assembled mono-layers of molecules on ITO substrates with appropriate direction and magnitude of dipole moment, improves the performance of organic solar cells [14] [15]. This method decreases the injection barrier between the HOMO level and the ITO and it also effectively changes the work function of ITO. Another way to increase the efficiency is the formation of an interfacial energy step [16] [17].

One particular interest is that the donor-acceptor heterojunction is formed from a blend of conjugated polymer with a fullerene derivative [18]-[23]. An example of promising OSCs, is a blend of the fullerene derivative [6, 6]-phenyl-C61 butyric acid methyl ester (PCBM) and regioregular poly (3-hexylthiophene) (P3HT) heterojunction, which has been experimentally studied earlier [24]. A phase-separated bulk heterojunction (BHJ) nanostructure of large interfacial area is formed from this blend [25]. A thin poly (3, 4-ethylenedionythiophene): poly (styrenesulfonate) (PEDOT:PSS) layer is used as an anode contact because the work function of PEDOT:PSS matches with the HOMO of P3HT and this allows for effective extraction of holes from the active layer [26]. The PEDOT:PSS layer planarizes the ITO surface without affecting the light absorption by the active layer significantly. PEDOT:PSS has high electrical conductivity and low temperature solution processability, which makes it an ideal hole transport material. Though it is used as a hole transport layer, its electrical inhomogeneity property prevents it to be an electron blocking layer [27]. Moreover, the hygroscopic and acidic nature of PEDOT:PSS can degrade the device performance. Metal oxides like $\mathrm{VO}_{\mathrm{x}}, \mathrm{NiO}_{\mathrm{x}}$ and $\mathrm{MnO}_{\mathrm{x}}$ have been used as a replacement of PEDOT:PSS but the rough interfaces formed by metal oxides can also degrade device performances [28] [29]. The future of P3HT:PCBM organic solar cells will depend on the improvement of their conversion efficiency. Currently organic solar cells shows relatively lower efficiency (3.5\% or lower) when compared to the inorganic solar cells. Therefore, more studies are needed to enhance and understand the conversion efficiency of these devices. In addition, the traditional equivalent OSC circuit used to describe OSC does not accurately describe devices that have incorporated novel interfacial layers [30].

The goal of this work is to investigate the properties of OSC devices with an added $\mathrm{AgO}_{\mathrm{x}}$ interfacial layer between the PEDOT:PSS and ITO and to develop a model that best describes this device. The added $\mathrm{AgO}_{\mathrm{x}}$ layer increases the fill-factor (FF), power conversion efficiency (PCE) and reduces the physical contact of PEDOT:PSS with ITO. While developing a revised model, we also revisit some earlier models for different solar cells. This methodology will correlate between theoretically constructed current-voltage (I-V) plots and experimental I-V plots. Then based on the I-V correlation results a model will be suggested that bests describes the P3HT:PCBM organic solar cell.

\section{Experimental Details}

The fabrication of the device consists of five layers. Figure 1 shows the device structure of the organic solar cell.

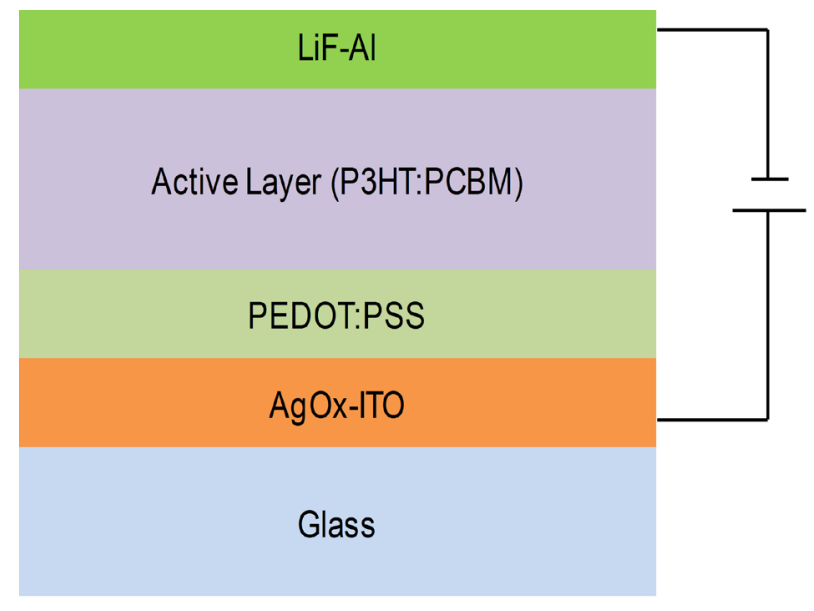

Figure 1. Device structure of the organic solar cell. 
Patterned ITO coated glass substrates were cleaned in ultrasonic baths of methanol, acetone and isopropanol, followed by $15 \mathrm{~min}$ ultraviolet ozone (UVO) treatment. On top of the ITO, $1 \mathrm{~nm}$ of Ag metal was deposited by thermal evaporation at a pressure of $\sim 10^{-7}$ Torr followed by 1 min UVO treatment. Using Ocean Optics double channel spectrometer (model DS200) optical transmittance of bare ITO and ITO with $\mathrm{AgO}_{\mathrm{x}}$ layer, were measured in 300 - $800 \mathrm{~nm}$ wavelength range. Electron acceptor material PCBM and electron donor P3HT were weighed $(1: 1 \mathrm{w} / \mathrm{w})$ and dissolved in 1, 2-dichlorobenzene (DCB). PEDOT:PSS solution was spin coated at $5000 \mathrm{rpm}$ for $60 \mathrm{~s}$. After that photoactive layers were spin-coated at $600 \mathrm{rpm}$ for $1 \mathrm{~min}$. It was then annealed at $120^{\circ} \mathrm{C}$ on a hot plate for 30 mins, which corresponds to a layer thickness of $250 \mathrm{~nm}$. Finally, $0.7 \mathrm{~nm}$ of LiF was thermally deposited followed by $80 \mathrm{~nm} \mathrm{Al} \mathrm{cathodes} \mathrm{in} \mathrm{vacuum.} \mathrm{During} \mathrm{thermal} \mathrm{evaporation} \mathrm{a} \mathrm{shadow} \mathrm{mask} \mathrm{was} \mathrm{used} \mathrm{to} \mathrm{define}$ $0.2 \mathrm{~cm}^{2}$ of active area. Under simulated AM 1.5 global solar irradiation photo current density-voltage (J-V) measurements were performed using a xenon-lamp solar simulator.

\section{Equivalent Circuit}

In order to understand the electrical behavior and observe how the device parameters changes with any kind of applied treatment (bias, illumination, etc.) to the device, it is modeled with discreet electrical components such as voltage or current sources, diodes and resistors. It provides a scientific and realistic physical explanation for the OPV behavior.

\subsection{The Single Diode Model}

PV solar cells typically can be represented by an equivalent circuit consisting of a single diode as shown in Figure 2. The resistor and current values depend on the illuminated area. But the dark current depends on the actual device area.

Assuming that, for voltage dependence of the current the Shockley diode equation can be used and $I_{D}$ is the current through the ideal diode $D$ then applying Kirchoff's current and voltage laws in currents nodes and voltage loops we can formulate the following equation:

$$
I=\left(I_{L}-\frac{V}{R_{S H}}\right) \frac{R_{S H}}{R_{S H}+R_{S}}-I_{0}\left[\exp \left(\frac{V+I R_{S}}{n k T / q}\right)-1\right] \cdot \frac{R_{S H}}{R_{S H}+R_{S}}
$$

Now, considering an ideal solar cell that comprises only ideal [31] diode $D$ in the dark so that $R_{S H}=\infty$ and $R_{S}=0$ then Equation (1) can be rewrite as:

$$
I_{D}=I_{0}\left[\exp \left(\frac{V}{n k T / q}\right)-1\right]
$$

Under illumination, the light generates a photo current $I_{L}$ which is simply added with the normal rectifying characteristics of the diode $D$ :

$$
I_{D}=I_{0}\left[\exp \left(\frac{V}{n k T / q}\right)-1\right]-I_{L}
$$

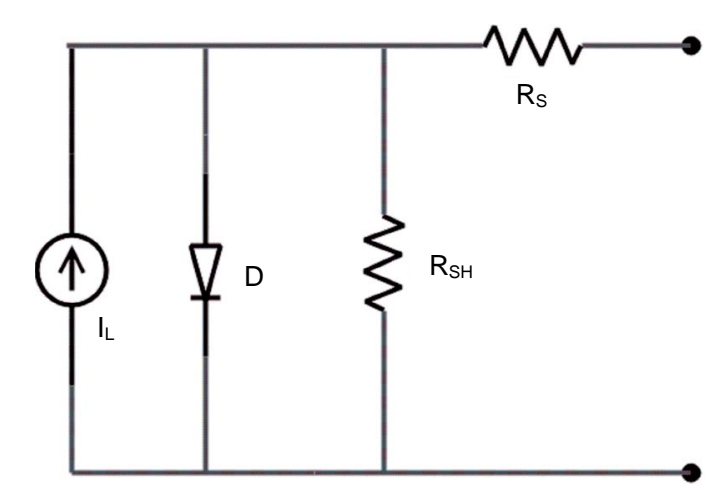

Figure 2. The single diode model equivalent circuit. 
By setting the output current to zero $(I=0)$ in Equation (1), we obtain:

$$
V_{O C}=\frac{n k T}{q} \ln \left(\frac{I_{L}-V_{O C} / R_{S H}}{I_{0}}+1\right)
$$

\subsection{The Two Diode Model}

The two-diode model can be described from the lumped parameters of Figure 3. Using the Shockley diode equations, we obtain:

$$
I=\left(I_{L}-\frac{V}{R_{S H}}\right) \frac{R_{S H}}{R_{S H}+R_{S}}-I_{01}\left[\exp \left(\frac{V+I R_{S}}{n k T / q}\right)-1\right] \frac{R_{S H}}{R_{S H}+R_{S}}-I_{02}\left[\exp \left(\frac{V+I R_{S}}{n k T / q}\right)-1\right] \frac{R_{S H}}{R_{S H}+R_{S}}
$$

Setting $I=0$, we get the equation for $V_{O C}$ which is

$$
V_{O C}=\frac{n k T}{q} \ln \left(\frac{I_{L}-V_{O C} / R_{S H}}{I_{01}-I_{02}}+1\right)
$$

Lower mobility and smaller charge carrier concentration lead to considerably smaller currents in most organic solar cells. In fact, both the dark and light currents are about 1000 times smaller; hence, the light current in these devices is about as large as the dark current in silicon devices. The dark current is still about 900 times smaller and according to Equation (6) a similar $V_{O C}$ is expected.

\section{Result and Discussion}

According to Equation (6), both the ideal diode $D$ and $R_{S H}$ are now the components that determine $V_{O C}$. This assumes that $R_{S H}$ is not very high and the device is in the dark and by applying a positive voltage across the cell electrodes a voltage drop can be created across $R_{S H}$ which equal to the voltage $V_{D}$ across the ideal diode $D$. The current that can pass through the diode $D$ at $V_{D}$ is determined by its I-V characteristic. The sum of the currents through $D$ and $R_{S H}$ yields the current through the electrodes of the solar cell for a given applied voltage. Upon illumination, the current source generates the current $I_{L}$ some of which passes through the diode where a voltage drop is generated that is big enough to allow the rest of $I_{L}$ to go through $R_{S H}$ if the electrodes are open. The same voltage can be measured with a voltmeter with high internal resistor across the device electrodes and is then termed open circuit voltage $V_{O C}$.

Figure 4 shows that the I-V characteristics changes if the shunt resistance varies between 100 ohm and 3000 Ohm assuming the shown values for $R_{S}, I_{L}$, and $I_{0}$. If $R_{S H}>1500 \mathrm{Ohm}$ the shape (FF, $V_{O C}$ ) of the IV curves remains virtually unchanged and the current shows no significant field dependence for negative bias.

However, clearly smaller $R_{S H}$ values have detrimental effects on the IV curve. The slope (field dependence) in the third quadrant increases considerably, $V_{O C}$ approaches zero and the FF reaches its theoretical minimum of 0.25 very quickly. However, the short circuit current is not affected since the current through the shunt can be neglected if $R_{S} \ll R_{S H}$.

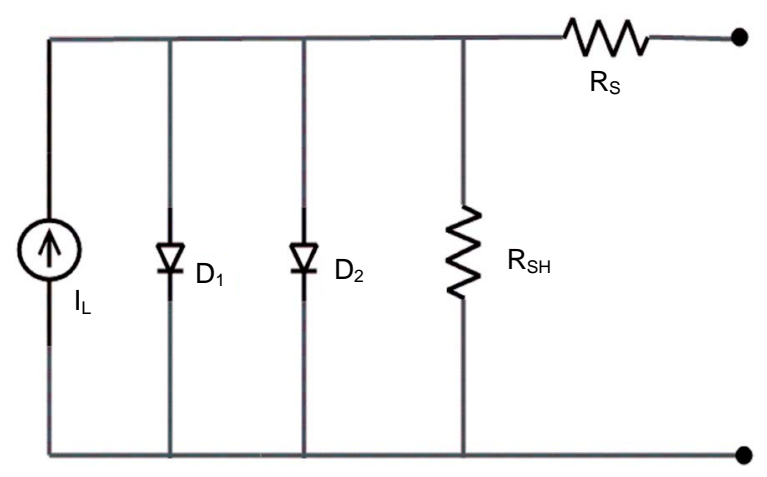

Figure 3. The tewo diode model equivalent circuit. 
Figure 5 shows the I-V characteristics with increasing series resistance, assuming the same parameters as above. While the slope in the third quadrant remains unchanged the slope in the first quadrant starts to decrease considerably when $R_{S}$ reaches the same order of magnitude as $R_{S H}$. The effect of the large $R_{S}$ even extends into the third quadrant thereby decreasing FF to its minimum.

Moreover, if the two resistors have similar values, the I-V curve is dominated by their Ohmic characteristics (the inverse slope in the 1 quadrant is equal to $R_{S}$ ) and the ideality factor or voltage dependence of $\mathrm{D}$ may then have little influence. Note that in contrast to the effect of $R_{S H}$ the short circuit current can decrease but the open circuit voltage cannot be affected at all—since there is no current through $R_{S}$ at $V_{O C}$.

Once all the parameters for the equivalent circuit are determined, using the raw data we have constructed simulated I-V plot in order to develop a model that best describe this particular OSC. Considering the effect of $R_{S H}$ and $R_{S}$ as discussed above, a resistor $R_{S 1}$ in series with one diode is added. $R_{S 1}$ accounts for the recombination of the carriers. Figure 6 shows the proposed model. The ideality factor $n$ for both of the diodes was assumed equal with an approximation corresponding to the Shockley-Read-Hall recombination current density in the space-charge region [32]. The current equation for the proposed two diode model is given by Equation (7).

$$
I=\left(I_{L}-\frac{V}{R_{S H}}\right) \frac{R_{S H}}{R_{S H}+R_{S}}-I_{01}\left[\exp \left(\frac{V+I R_{S}+I R_{S 1}}{n k T / q}\right)-1\right] \frac{R_{S H}}{R_{S H}+R_{S}}-I_{02}\left[\exp \left(\frac{V+I R_{S}}{n k T / q}\right)-1\right] \frac{R_{S H}}{R_{S H}+R_{S}}
$$

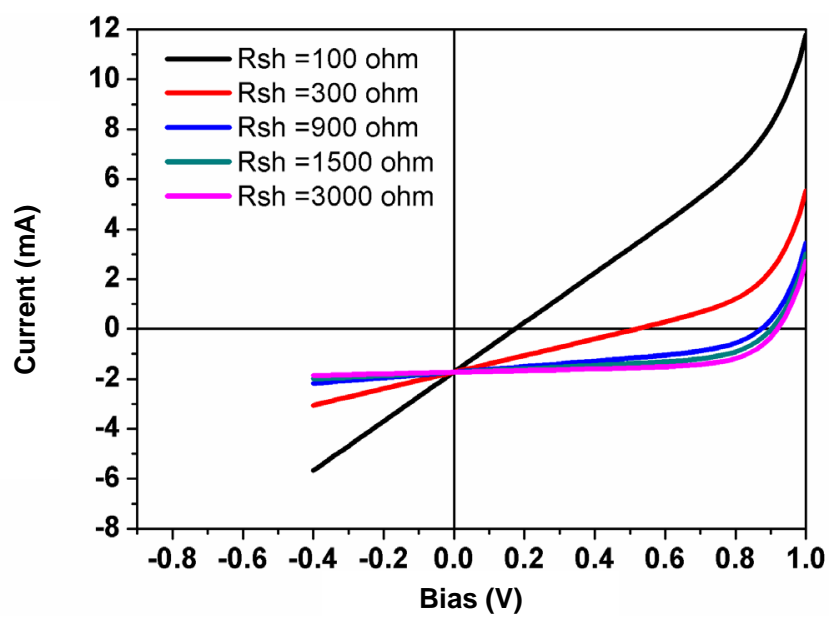

Figure 4. Effect of $R_{S H}$ with hypothetical values of $R_{S}=1 \mathrm{Ohm}$ (device area $0.2 \mathrm{~cm}^{2}$ ), under $100 \mathrm{~mW} / \mathrm{cm}^{2}$ illumination intensity.

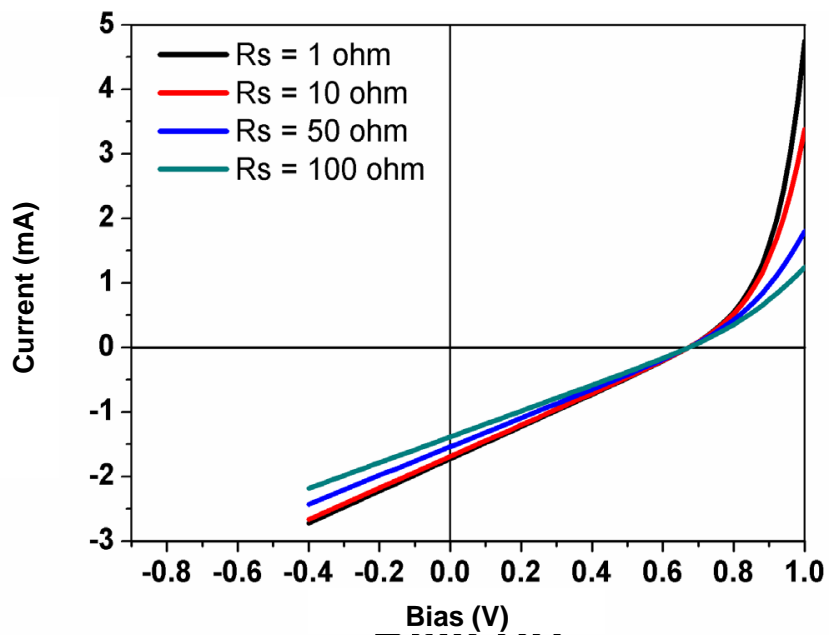

Figure 5. Effect of $R_{S}$ with hypothetical values of $R_{S H}=400 \mathrm{Ohm}$ (device area $0.2 \mathrm{~cm}^{2}$ ), under $100 \mathrm{~mW} / \mathrm{cm}^{2}$ illumination intensity. 


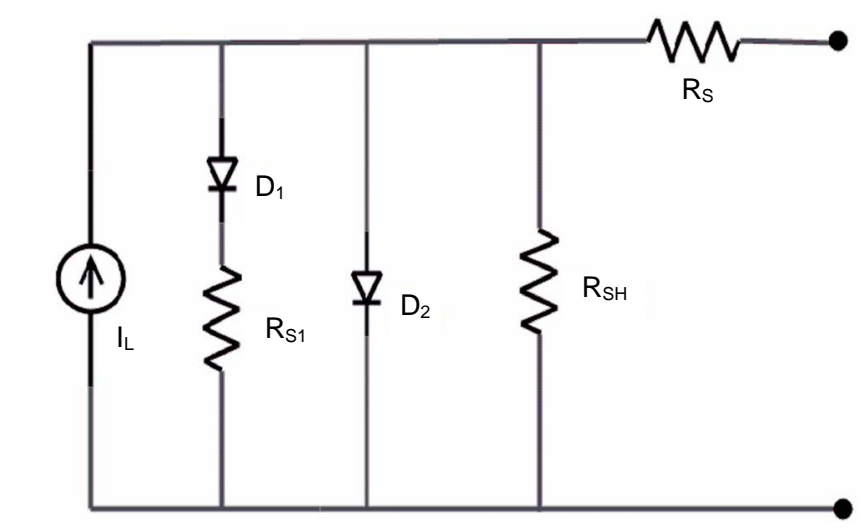

Figure 6. Proposed two diode model equivalent circuit.

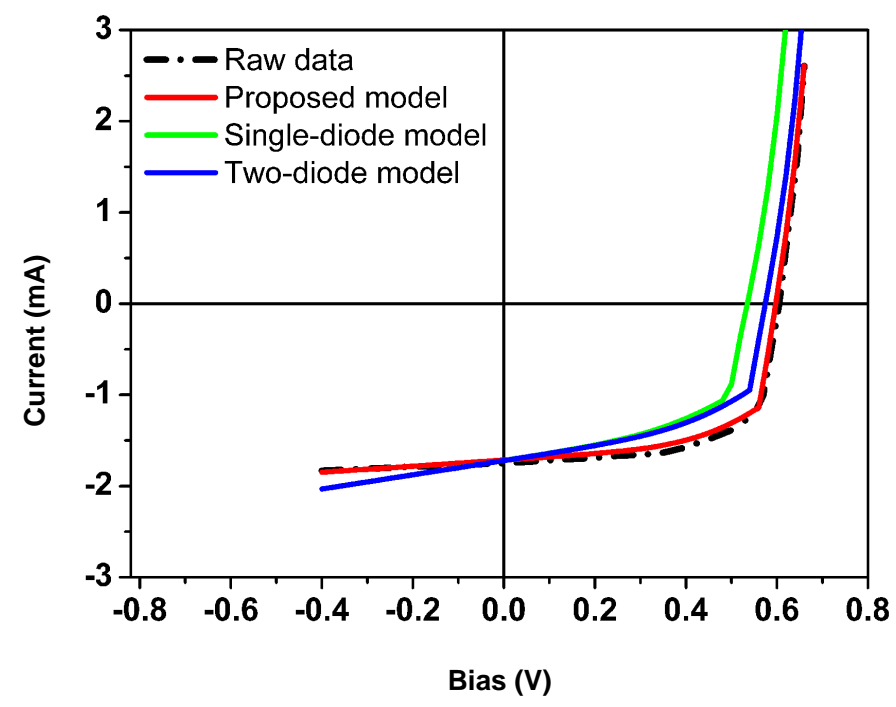

Figure 7. Simulation and experimental curves of I-V characteristics for the organic solar cell under $100 \mathrm{~mW} / \mathrm{cm}^{2}$ illumination intensity (device are $0.2 \mathrm{~cm}^{2}$ ).

Figure 7 shows the I-V plots for experimental data and simulated plots for the proposed model, single and two diode models under $100 \mathrm{~mW} / \mathrm{cm}^{2}$ illumination intensity. It is observed that the $\mathrm{I}-\mathrm{V}$ characteristics generated from our proposed model fits well with the experimental result. The average percentage variation is $2.38 \%$. Using a $\mathrm{AgO}_{\mathrm{x}}$ interfacial layer between PEDOT:PSS and ITO increases the power conversion efficiency by $28 \%$.

\section{Conclusion}

The device with added $\mathrm{AgO}_{\mathrm{x}}$ interfacial layer showed 3.5\% PCE and 33\% increase of FF. Earlier single diode and two diode models were unable to describe the device behavior; hence, a two diode model was developed. Based on the experimental values and the simulated result under same illuminated intensity, the two diode models correlated with the experimental result showed only a $2.4 \%$ variation.

\section{Acknowledgements}

This research was partially supported by the National Science Foundation (C. Ying, Grant No. DMR-0902277).

\section{References}

[1] Brabec, C.J., Sariciftci, N.S. and Hummelen, J.C. (2001) Plastic Solar Cells. Advanced Functional Materials, 11, $15-26$. 
http://dx.doi.org/10.1002/1616-3028(200102)11:1<15::AID-ADFM15>3.0.CO;2-A

[2] Krebs, F.C. (2009) Fabrication and Processing of Polymer Solar Cells: A Review of Printing and Coating Techniques. Solar Energy Materials and Solar Cells, 93, 394-412. http://dx.doi.org/10.1016/j.solmat.2008.10.004

[3] Chen, H.Y., Hou, J., Zhang, S., Liang, Y., Yang, G., Yang, Y., Yu, L., Wu, Y. and Li, G. (2009) Polymer Solar Cells with Enhanced Open-Circuit Voltage and Efficiency. Nature Photonics, 3, 649-653. http://dx.doi.org/10.1038/nphoton.2009.192

[4] Kim, J.Y., Lee, K., Coates, N.E., Moses, D., Nguyen, T.-Q., Dante, M. and Heeger, A.J. (2007) Lithography and Fabrication of Frictional Tiers on Poly(dimethylsiloxane) Using Atomic Force Microscopy. Science, 317, 222-225. http://dx.doi.org/10.1126/science.1141711

[5] Krebs, F.C. (2005) Alternative PV: Large Scale Organic Photovoltaics. Alternative PV: Large Scale Organic Photovoltaics, Refocus, 6, 38-39. http://dx.doi.org/10.1016/S1471-0846(05)70399-1

[6] Ma, H., Yip, H.L., Huang, F. and Jen, A.K.-Y. (2010) Interface Engineering for Organic Electronics. Advanced Functional Materials, 20, 1371-1388. http://dx.doi.org/10.1002/adfm.200902236

[7] He, Z., Zhong, C., Su, S., Xu, M., Wu, H. and Cao, Y. (2012) Enhanced Power-Conversion Efficiency in Polymer Solar Cells Using an Inverted Device Structure. Nature Photonics, 6, 591-595. http://dx.doi.org/10.1038/nphoton.2012.190

[8] Li, G., Zhu, R. and Yang, Y. (2012) Polymer Solar Cells. Nature Photonics, 6, 153-161. http://dx.doi.org/10.1038/nphoton.2012.11

[9] Spanggaard, H. and Krebs, F.C. (2004) A Brief History of the Development of Organic and Polymeric Photovoltaics. Solar Energy Materials and Solar Cells, 83, 125-146. http://dx.doi.org/10.1016/j.solmat.2004.02.021

[10] Na, S.-I., Kim, S.-S., Jo, J. and Kim, D.-Y. (2008) Efficient and Flexible ITP-Free Organic Solar Cells Using Highly Conductive Polymer Anodes. Advanced Materials, 20, 4061-4067. http://dx.doi.org/10.1002/adma.200800338

[11] Cho, Y.J., Lee, J.Y., Chin, B.D. and Forrest, S.R. (2013) Polymer Bulk Heterojunction Photovoltaics Employing a Squaraine Donor Additive. Organic Electronics, 14, 1081-1085. http://dx.doi.org/10.1016/j.orgel.2013.01.014

[12] Brabec, C.J., Shaheen, S.E., Winder, C., Sariciftci, N.S. and Denk, P. (2002) Effect of LiF/Metal Electrodes on the Performance of Plastic Solar Cells. Applied Physics Letters, 80, 1288-1290. http://dx.doi.org/10.1063/1.1446988

[13] Ramsdale, C.M., Barker, J.A., Arias, A.C., MacKenzie, J.D., Friend, R.H. and Greenham, N.C. (2002) The Origin of the Open-Circuit Voltage in Polyfluorene-Based Photovoltaic Devices. Journal of Applied Physics, 92, 4266-4270. http://dx.doi.org/10.1063/1.1506385

[14] Khodabakhsh, S., Sanderson, B.M., Nelson, J. and Jones, T.S. (2006) Using Self-Assembling Dipole Molecules to Improve Charge Collection in Molecular Solar Cells. Advanced Functional Materials, 16, 95-100. http://dx.doi.org/10.1002/adfm.200500207

[15] Kim, J.S., Park, J.H., Lee, J.H., Jo, J., Kim, D.Y. and Cho, K. (2007) Control of the Electrode Work Function and Active Layer Morphology via Surface Modification of Indium Tin Oxide for High Efficiency Organic Photovoltaics. Applied Physics Letters, 91, Article No. 112111. http://dx.doi.org/10.1063/1.2778548

[16] Chang, M.-Y., Wu, C.-S., Chen, Y.-F., Hsieh, B.-Z., Huang, W.-Y., Ho, K.-S., Hsieh, T.-H. and Han, Y.-K. (2008) Polymer Solar Cells Incorporating One-Dimensional Polyaniline Nanotubes. Organic Electronics, 9, 1136-1139. http://dx.doi.org/10.1016/j.orgel.2008.08.001

[17] Subbiah, J., Kim, D.Y., Hartel, M. and So, F. (2010) MoO3/TFB Double Interlayer Effect on Polymer Solar Cells. Applied Physics Letters, 96, Article No. 063303. http://dx.doi.org/10.1063/1.3310013

[18] Kenji, K., Pacios, R. and Poplavskyy, D. (2006) Solar Energy Materials and Solar Cells. Solar Energy Materials and Solar Cells, 90, 3520-3530.

[19] Janssen, R.A.J., Hummelen, J.C. and Saritiftci, N.S. (2005) Polumer-Fullerene Bulk Heterojunction Solar Cells. MRS Bulletin, 30, 33-36. http://dx.doi.org/10.1557/mrs2005.6

[20] Brabec, C.J., Hauch, J.A., Schilinsky, P. and Wladauf, C. (2005) Production Aspects of Organic Photovoltaics and Their Impact on the Commercialization of Devices. MRS Bulletin, 30, 50-52. http://dx.doi.org/10.1557/mrs2005.10

[21] Coakley, K.M. and McGehee, M.D. (2004) Conjugated Polymer Photovoltaic Cells. Chemistry of Materials, 16, 45334532. http://dx.doi.org/10.1021/cm049654n

[22] Jørgensen, M., Norrman, K. and Krebs, F.C. (2008) Stability/Degradation of Polymer Solar Cells. Solar Energy Materials and Solar Cells, 92, 686-714. http://dx.doi.org/10.1016/j.solmat.2008.01.005

[23] Shaneen, S.E., Brabec, C.J., Sariciftci, N.S., Padinger, F., Fromherz, T. and Hummelen, J.C. (2001) 2.5\% Efficient Organic Plastic Solar Cells. Applied Physics Letters, 78, 841. http://dx.doi.org/10.1063/1.1345834

[24] Dang, M.T., Hirsch, L. and Wantz, G. (2011) P3HT:PCBM, Best Seller in Polymer Photovoltaic Research. Advanced 
Materials, 23, 3597-3602. http://dx.doi.org/10.1002/adma.201100792

[25] Choy, W.C.H. (2013) Organic Solar Cells: Materials and Device Physics, Springer, London, 5. http://dx.doi.org/10.1007/978-1-4471-4823-4

[26] Arias, A.C., Granstrom, M., Thomas, D.S., Petritsch, K. and Friend, R.H. (1999) Doped Conducting-Polymer-Semiconducting-Polymer Interfaces: Their Use in Organic Photovoltaic Devices. Physical Review B, 60, 1854-1860. http://dx.doi.org/10.1103/PhysRevB.60.1854

[27] Pingree, L.S.C., MacLeod, B.A. and Ginger, D.S. (2008) The Changing Face of PEDOT:PSS Films: Substrate, Bias, and Processing Effects on Vertical Charge Transport. The Journal of Physical Chemistry C, 112, 7922-7927. http://dx.doi.org/10.1021/jp711838h

[28] Yan, H., Lee, P., Armstrong, N.R., Graham, A., Evmenenko, G.A., Dutta, P. and Marks, T.J. (2005) High-Performance Hole-Transport Layer for Polymer Light-Emitting Diodes. Implementation of Organosiloxane Cross-linking Chemistry in Polymeric Electroluminescent Devices. The Journal of the American Chemical Society, 127, 3172-3183. http://dx.doi.org/10.1021/ja044455q

[29] Shrotriya, V., Li, G., Chu, C.-W. and Yang, Y. (2006) Transition Metal Oxides as the Buffer Layer for Polymer/Photovoltaic Cells. Applied Physics Letters, 88, Article ID: 073508. http://dx.doi.org/10.1063/1.2174093

[30] Das, S. and Alford, T.L. (2014) Improved Efficiency of P3HT:PCBM Solar Cells by Incorporation of Silver Oxide Interfacial Layer. Journal of Applied Physics, 116, Article No. 044905. http://dx.doi.org/10.1063/1.4891246

[31] Irwin, M.D., Buchholz, B., Hains, A.W., Chang, R.P.H. and Marks, T.J. (2008) p-Type Semiconducting Nickel Oxide as an Efficiency Enhancing Anode Interfacial Layer in Polymer Bulk Hererojunction Solar Cells. Proceedings of the National Academy of Sciences of the United States of America, 105, 2783-2787. http://dx.doi.org/10.1073/pnas.0711990105

[32] Vasilopoulou, M., Soultati, A., Georgeiadou, D.G., Stergiopoulos, T., Palilis, L.C., Kennou, S., Stathopoulos, N.A., Davazoglou, D. and Argitis, P. (2014) Hydrogenated Under-Stoichiometric Tungsten Oxide Anode Interlayers for Efficient and Stable Organic Photovoltaics. Journal of Materials Chemistry A, 2, 1738-1749.

http://dx.doi.org/10.1039/C3TA13975A 